\title{
Modeling the effect of solvent on the possibility of the formation the $\mathrm{HSO}_{3}{ }^{+}$cation
}

\author{
(C) Andrey A. Degtyarev, ${ }^{1{ }^{+}}$and Daria P. Rostova ${ }^{2}$ \\ ${ }^{1}$ Department of Chemistry and Chemical Technologies. Tambov State Technical University. \\ Soviet St., 106. Tambov, 392000. Russia. Phone: ${ }^{1)}+7$ (4752) 63-44-44; ${ }^{2)}+7$ (4752) 63-44-44. \\ E-mail: ${ }^{1)}$ ad.dycost@gmail.com; ${ }^{2)}$ rostova.dariya@yandex.ru
}

\begin{abstract}
*Supervising author; ${ }^{+}$Corresponding author Keywords: $\mathrm{HSO}_{3}{ }^{+}, \mathrm{H}_{3} \mathrm{SO}_{4}{ }^{+}$DFT, COSMO, oleum, dielectric constant, solvation effect.
\end{abstract}

\begin{abstract}
The possibility of describing the reactions of heterolytic dissociation sulfuric acid and the further conversion of the $\mathrm{H}_{3} \mathrm{SO}_{4}{ }^{+}$cation to $\mathrm{HSO}_{3}{ }^{+}$by the density functional theory method was studied. By comparing with the calculated and experimental data, a functional and a basic set were selected for modeling these reactions.

The influence of the solvent on the course of the studied reactions was studied: based on COSMO continuum model (implicit solvent accounting) and explicit solvent accounting (introduction of particles participating in the reaction into the solvation shell of four sulfuric acid molecules). It was shown that individually neither the continuum model nor the explicit solvent accounting can adequately describe the reactions under study from the aspect of energy effects.

It was determined that the reactions studied can occur only in strongly polar solvents. The effect of the content of sulfuric trioxide in oleum on the particle formation energy of $\mathrm{H}_{3} \mathrm{SO}_{4}{ }^{+}$and $\mathrm{HSO}_{3}{ }^{+}$was studied. It was shown that an increase in the concentration of sulfuric trioxide from 0 to $15 \%$ reduces the energy spent on the formation of $\mathrm{H}_{3} \mathrm{SO}_{4}{ }^{+}$and $\mathrm{HSO}_{3}{ }^{+}$particles by 2.5 and $3.5 \mathrm{~kJ} / \mathrm{mol}$, which leads to an increase in the equilibrium constants of the formation reactions of these products by 2.74 and 4.11 times.

An approximate estimate is made of the equilibrium constant of the reaction of formation of the $\mathrm{HSO}_{3}{ }^{+}$ cation, equal to $\sim 10^{-7}-10^{-8}$.

It was shown that particles of $\mathrm{HSO}_{3}{ }^{+}$and $\mathrm{SO}_{3}$ in sulfuric acid solutions exist in the form of associates with sulfuric acid, through the sulfur atom $\mathrm{SO}_{3} / \mathrm{HSO}_{3}{ }^{+}$and oxygen $\mathrm{H}_{2} \mathrm{SO}_{4}$, in which the $\mathrm{S} \cdots \mathrm{O}$ distance is 1.98 $\AA$ for $\mathrm{SO}_{3}$ and $1.9 \AA$ for $\mathrm{HSO}_{3}^{+}$.

\section{References}

[1] R. Bruckner. Advanced Organic Chemistry: Reaction Mechanisms. Academic Press. 2001. 636p.

[2] T.I. Okuyama, H. Maskill. Organic Chemistry: A Mechanistic Approach. OUP Oxford. 2013.

[3] A.I. Kourdioukov, V.F. Khayrutdinov, F.M. Gumerov, A.R. Gabitova, V.G. Uryadov, and A.F. Mingaliev. The triplet biradical states of the arenes, as a basis for paramagnetic centers of asphaltenes and a source of soft radical thermolysis in SCF-extraction processes for processing super viscous oil and resinasphaltene mixtures Butlerov Communications. 2017. Vol.52. No.10. P.1-16. https://doi.org/10.37952/ROI-jbc-02/17-52-10-1

[4] A.A. Degtyarev, and A.V. Trishina. Research the sulfonation mechanism of urea in oleum by density functional theory calculation. Butlerov Communications. 2019. Vol.59. No.8. P.32-39. https://doi.org/10.37952/ROI-jbc-02/19-59-8-32

[5] V.B. Kazanskii, V.N. Solkan. Solvation of Protons in Anhydrous H2SO4 as the Main Factor Determining Its Superacidic Properties. Kinetics and Catalysis. 2000. Vol.41. No.1. P.38-41. DOI: $0.1007 / \mathrm{BF} 02756138$

[6] V.B. Kazanskii, V.N. Solkan. Proton solvation and self-dissociation of $100 \%$ sulfuric acid: The quantumchemical analysis. Phys. Chem. Chem. Phys. 2003. Vol.5. P.31-35. DOI: 10.1039/b209415k

[7] O.V. Lebedeva, E.A. Malakhova, A.V. Kuzmin, A.N. Chesnokova, E.I. Sipkina, T.V. Raskulova, Yu.N. Pozhidaev, V. Kulshrestha. Sulfonation of styrene-allyl glycidyl ether copolymers. Proceedings of universities applied chemistry and biotechnology. 2018. Vol.8. P.13-23. DOI: 10.21285/2227-29252018-8-4-13-23

[8] G.C. Gerrans, P. Hartmann-Petersen, R. Hartmann-Petersen. Encyclopedia of Science and Technology. New Africa Books. 2004. P.129.
\end{abstract}


[9] A. Klamt, G. Schü̈̈rmann. COSMO: A New Approach to Dielectric Screening in Solvents with Explicit Expressions for the Screening Energy and its Gradient. J. Chem. Soc. Perkin Trans. 1993. Vol.2. P.799805. DOI:10.1039/P29930000799

[10] G. Warlafen. Raman Spectral Studies of Oleums. The Journal of Chemical Physics. 1964. Vol.40. P.2326-2341. DOI: 10.1063/1.1725511

[11] A. Klamt, F. Eckert, W. Arlt. COSMO-RS: An Alternative to Simulation for Calculating Thermodynamic Properties of Liquid Mixtures. Annual review of chemical and biomolecular engineering. 2010. Vol.1. No.1. P.101-122. DOI: 10.1146/annurev-chembioeng-073009-100903

[12] A.R. Allouche. Gabedit - A graphical user interface for computational chemistry softwares, Journal of Computational Chemistry. 2011. Vol.32. P.174-182. DOI: $10.1002 / j c c .21600$

[13] M.J. Vainio, M.S. Johnson. Generating Conformer Ensembles Using a Multiobjective Genetic Algorithm. J Chem Inf Model. 2007. Vol.47. P.2462-2474. DOI: 10.1021/ci6005646

[14] G.B. Rocha, R.O. Freire, A.M. Simas, J.J.P. Stewart. RM1: A Reparameterization of AM1 for H, C, N, O, P, S, F, Cl, Br, and I. J. Comp. Chem. 2006. Vol.27. No.10. P.1101-1111. DOI: 10.1002/jcc.20425

[15] J.J.P. Stewart. MOPAC2016. Stewart Computational Chemistry. Colorado Springs. 2016. http://openmopac.net.

[16] J.P. Perdew, K. Burke, M. Ernzerhof. Generalized Gradient Approximation Made Simple. Phys. Rev. Lett. 1996. Vol.77. No.18. P.3865-3868. DOI: 10.1103/PhysRevLett.77.3865

[17] D. Laikov. A new class of atomic basis functions for accurate electronic structure calculations of molecules. Chemical Physics Letters. 2005. Vol.416. P.116-120. DOI: 10.1016/j.cplett.2005.09.046

[18] D.N. Laikov, Y.A. Ustynyuk. PRIRODA-04: a quantum-chemical program suite. New possibilities in the study of molecular systems with the application of parallel computing. Russ. Chem. Bull. 2005. Vol.54. P.820-826. DOI: 10.1007/s11172-005-0329-x

[19] S. Grimme, S. Ehrlich, L. Goerigk. Effect of the damping function in dispersion corrected density functional theory. J Comput Chem. 2011. Vol.32. P.1456-1465. DOI: 10.1002/jcc.21759

[20] S. Grimme, J. Antony, S. Ehrlich, H.J. Krieg. A consistent and accurate ab initio parametrization of density functional dispersion correction (DFT-D) for the 94 elements H-Pu. J. Chem. Phys. 2010. Vol.132. P.154104. DOI: 10.1063/1.3382344

[21] M. Head-Gordon, J. Pople, M. Frisch. MP2 energy evaluation by direct methods. Chemical Physics Letters. 1988. Vol.153. No.6. P.503-506. DOI: 10.1016/0009-2614(88)85250-3

[22] C. Lee, W. Yang, R.G. Parr. Development of the Colle-Salvetti correlation-energy formula into a functional of the electron density. Phys. Rev B. 1988. Vol.37. P.785-789. DOI: 10.1103/PhysRevB.37.785

[23] D.E. Woon, Jr.T.H. Dunning. Gaussian basis sets for use in correlated molecular calculations. III. The atoms aluminum through argon. J. Chem. Phys. 1993. Vol.98. P.1358-1371. DOI: 10.1063/1.464303

[24] F. Weigend, A. Kohn, C. Hattig. Efficient use of the correlation consistent basis sets in resolution of the identity MP2 calculations. J. Chem. Phys. 2002. Vol.116. P.3175-3183. DOI: 10.1063/1.1445115

[25] F. Weigend. Accurate Coulomb-fitting basis sets for H to Rn. Phys. Chem. Chem. Phys. 2006. Vol.8. P.1057-1065. DOI: 10.1039/B515623H

[26] F. Neese. The ORCA program system. Wiley interdisciplinary Reviews: Computational Molecular Science. 2012. Vol.2. No.1. P.73-78. DOI: $10.1002 / \mathrm{wcms} .81$

[27] B.M. Bode, M.S. Gordon. MacMolPlt: a graphical user interface for GAMESS. J. Mol. Graphics Mod. 1998. Vol.16. No.3. P.133-138. DOI: 10.1016/S1093-3263(99)00002-9

[28] A. Givan, A. Loewenschuss, K.J. Nielsen, M. Rozenberg. FTIR and computational studies of pure and water containing SO3 species in solid argon matrices. Journal of Molecular Structure. 2007. Vol.830. No.1. P.21-34. DOI: 10.1016/j.molstruc.2006.06.027

[29] H. Arstila, K. Laasonen, A. Laaksonen. Ab initio study of gas-phase sulphuric acid hydrates containing 1 to 3 water molecules. J. Chem. Phys. 1998. Vol.108. No.3. P.1031-1039. DOI: 10.1063/1.475496 